\title{
(2) \\ In situ mining through leaching: experimental methodology for evaluating its implementation and economic considerations
}

\author{
by C. Bahamóndez*, R. Castro*, T. Vargas ${ }^{\dagger}$, and \\ E. Arancibia*
}

\section{Synopsis}

Rising costs in the mining industry have necessitated a search for alternative methods for the recovery of metals from deposits that are no longer economically or environmentally exploitable by conventional mining. These alternative methods include in situ mining.

A laboratory model was developed and an experimental programme undertaken to determine the effect of temperature, aeration, material compression, and material extraction on copper recovery by in situ leaching using $\mathrm{H}_{2} \mathrm{SO}_{4}$ and $\mathrm{Fe}^{3+}$. Recovery was estimated using the shrinking core model. Based on the experimental results and recovery estimations, an economic evaluation was completed comparing in situ mining with conventional mining methods.

\section{Keywords}

mining methods; in situ leaching; copper; laboratory model; experimental protocol. with the ore and poor aeration (Gorman et al., 2004), which makes the method uneconomic. Therefore, an in situ mining (ISM) method has recently been proposed, which integrates conventional underground mining method(s) and ISL in a novel way (Castro et al., 2013).

In the ISM method, blasted rock in a large stope is irrigated with a leaching solution, if the sublevel stoping (SLS) method was employed to access the orebody. The leaching process is carried out taking into consideration, for example, the ventilation and extraction system of a large stope, where the ore could be compacted over time due to the characteristics of the SLS method. It is expected that ISM will improve on the metallurgical recovery obtained with ISL through the incorporation of mining procedures and the control of metallurgical variables such as degree of compression, removal of material, temperature, and ventilation.

In this study, a laboratory model and an experimental methodology were developed to evaluate the influence of the main operational variables on the ISM method for copper sulphide deposits. Continuous samples of the pregnant leach solution (PLS) were measured and analysed for $\mathrm{pH}$, redox potential, and dissoluble copper by atomic absorption spectrometry. During leaching of a copper sulphide sample, the gallery was aerated using an air pump. The adjustment of copper curves within the shrinking core kinetic model over time showed that all experiments exhibited a diffusional control mechanism.

\footnotetext{
* Department of Mining Engineering, Advanced Mining Technology Center, University of Chile, Chile.

+ Department of Chemical Engineering and Biotechnology, Advanced Mining Technology Center, University of Chile, Chile.

$\mp$ CODELCO Chile, Chile.

(C) The Southern African Institute of Mining and Metallurgy, 2016. ISSN 2225-6253. Paper received Aug. 2015; revised paper received Nov. 2015.
} 


\section{In situ mining through leaching}

\section{In situ leaching}

ISL involves irrigating an ore deposit with a leaching solution through injection wells. The injected solution permeates through channels in the ore and solubilizes the metal(s) of interest. The PLS is then returned to the surface through recovery wells to be processed (Figure 1) (NRC, 1997a).

According to the literature (Morais et al., 2008; Venter et al., 2009), there are many similarities in the leaching processes for copper and uranium deposits. Solutions used in both cases are either acid or alkaline, with the most common being sulphuric acid with the addition of an oxidizing agent. Moreover, for both copper and uranium, injection and recovery wells are used to irrigate the orebody and recover the PLS (Llorente, 1991). In 2013, 47\% of the world's uranium produced was produced through the ISL method (WNA, 2014). Despite the resemblances to uranium extraction, the recovery of copper by ISL is less satisfactory. Some of the more likely reasons include the difference in particle size, control of solutions leaks, and mineralogy.

The literature and case study show (Gorman et al., 2004; Pradhan et al., 2008) that the variability of metallurgical recoveries through the ISL is associated with low or no control of geometallurgical variables such as fragmentation, aeration, and temperature. To overcome these deficiencies, the ISM method, in which leaching and conventional underground mining methods are integrated in a novel way, was proposed (Castro et al., 2013).

\section{In situ mining method}

As shown in Figure 1, the development for ISM is similar to the SLS method, but the broken material is irrigated inside the stope instead of being loaded and hauled to the surface (Castro et al., 2013). ISM considers that only the material corresponding to the increase in volume due to blasting will be transferred to the surface. Consequently, mining and processing costs would decrease significantly due to the reduction in the amount of material that needs to be moved and elimination of the need for comminution processes. In addition, the lower impact on the surface due to less waste production and better prevention and monitoring of solution leakages (compared with ISL, since the irrigation of the mineral is delimited by the stope and is located underground), delivers environmental benefits. Furthermore, ISM allows a better control of fragmentation by blasting than
ISL, by increasings the mineral surface exposed to the leaching solution, improving the permeability, and thus enabling control of other variables: temperature, aeration, and material extraction.

The ISM method consists of the following unit operations: drilling and blasting, loading and hauling, ventilation, and stope irrigation.

Drilling and blasting is the first fragmentation process that will increase the mineral surface exposed to the leaching solution as well as the permeability of the ore to be irrigated. The blasting design should be aimed at obtaining the degree of fragmentation that minimizes the costs and maximizes the copper recovery. Loading and haulage is limited to removing the swell material. In the case of channelling or reduction in permeability, constant extraction of material at drawpoints could probably improve recovery by reordering the fragments and creating high-permeability zones.

The application of air flow provides the required oxygen to increase sulphide copper oxidation and to improve the activity of leaching microorganisms (Lorca, 2004; Ghorbani et al., 2011). This effect has been observed at the Miami mine in Arizona, USA, where maintaining an efficient ventilation system greatly contributed to the copper recovery (Herrera, 1987). The aeration requirements should therefore be evaluated with respect to the leaching process parameters (i.e. mineralogy) (Wu et al., 2006).

The irrigation system must allow homogenous irrigation of the material as well as consistent concentration of the leaching solution inside the stope. For the irrigation, it is important to consider the drilling of broken material and intubation of the wells. The set-up proposed for ISM is shown in Figure 1. The influence of mining variables was studied (air flow, temperature, and granular density) through controlled experiments, and the results are described in subsequent sections.

\section{Experimental methodology}

\section{Model design}

A laboratory model (Figure 2) was designed and constructed to evaluate the effect of various mining and metallurgical parameters on copper recovery using the ISM method. The main structure of the model was a high-density polyethylene cylinder $700 \mathrm{~mm}$ in height and $400 \mathrm{~mm}$ in diameter. A drawbell, made of Robalon, and a gallery were attached to the
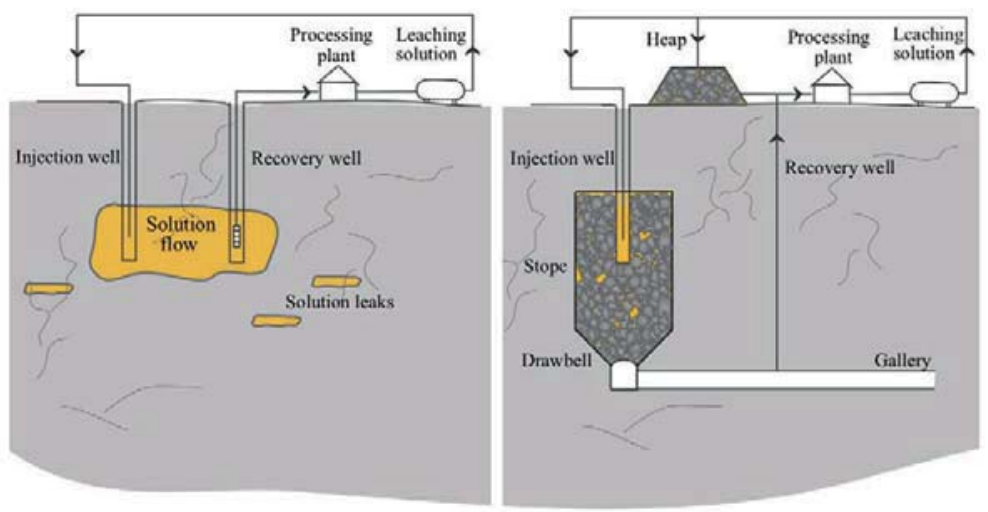


\section{In situ mining through leaching}

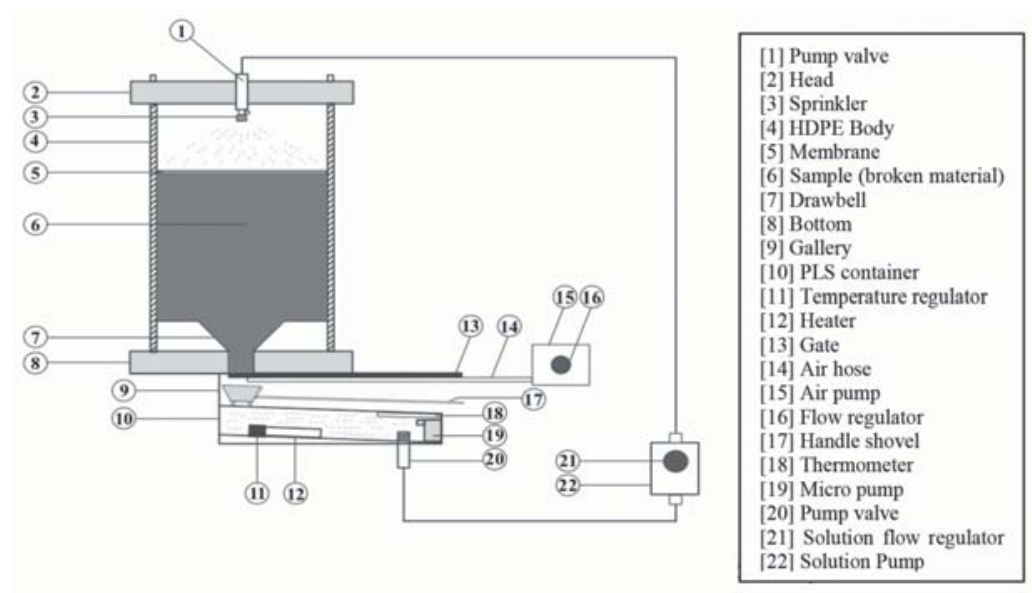

Figure 2-Schematic representation of the laboratory model

base of the cylinder for extraction of material. A container for the PLS was placed under the gallery. To ensure the constant recirculation of the PLS, a pump was incorporated next to the PLS container. To investigate the effect of ventilation, an air pump was added to the model. A heater and temperature regulator were used for temperature control, and a hydraulic press to investigate the effect of compression of the material. Figure 3 shows photographs of the laboratory model.

As shown in Figure 4A, a stainless steel plug closed the drawbell and prevented movement of material during leaching, but enabled drip-feeding of PLS. An acrylic gallery was placed under the drawbell. The gallery, designed with a $5.5^{\circ}$ inclination, included a set of holes to allow the drainage of the PLS into the container.

The laboratory model was designed to allow a vertical load to be applied to the confined material. The model dimensions also minimized the effect of the wall, avoiding the solution flowing through the pipe rather than the material (Llorente, 1991). The model had a capacity to contain 75$80 \mathrm{~kg}$ of crushed sample.

\section{Mineral samples}

An ore sample was obtained from a copper mine located in the Atacama region, Chile. The sample was crushed using a roller crusher and then classified using four sized sieves (Table I). The size distribution was arbitrarily defined for this research.

The samples granulometry shown in Figure 5 was obtained by crushing. The uniformity index $(d 60 / d 10)$ of 2.4 reveals a well-graded distribution of samples.

Copper grade was estimated at $0.6 \%$ by X-ray fluorescence spectrometry (Table II). Among all copper species observed by X-ray diffraction (1.9\% of the total), $1.2 \%$ corresponded to secondary sulphides and $0.7 \%$ to primary sulphides (Figure 6). No copper oxides were identified in the sample. Optical microscopy revealed the presence of molybdenum as $\mathrm{MoS}_{2}$ and titanium, as $\mathrm{TiO}_{2}$.

\section{Leaching experiments}

The leaching experiments were performed using $75 \mathrm{~kg}$ of sample. Leaching solutions were prepared with reagent-grade chemicals and distilled water. The leaching solution contained $20 \mathrm{~g} / \mathrm{L} \mathrm{H}_{2} \mathrm{SO}_{4}$ and $3 \mathrm{~g} / \mathrm{L}$ of $\mathrm{Fe}$ (III) as the oxidizing agent. Sulphuric acid was employed to maintain the desired $\mathrm{pH}(1.8-2.0)$. Samples of the solution were continuously taken from the PLS container to determine the $\mathrm{pH}$, Eh, and copper concentration by atomic absorption spectrometry.
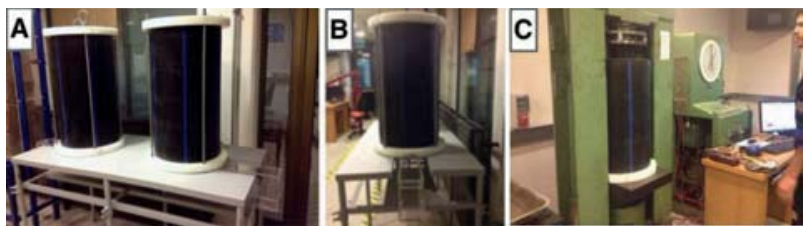

Figure 3-Lateral (A) and front view (B) of the laboratory model, and sample compression by hydraulic press (C)

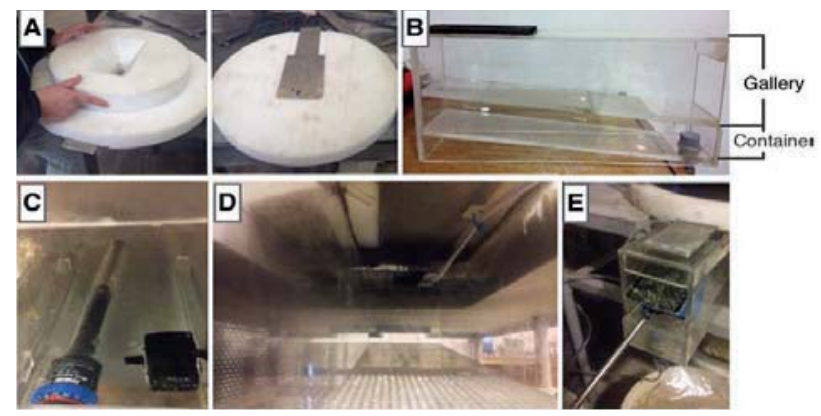

Figure 4-Drawbell (A), gallery and PLS container (B), heater and micro pump incorporated into the solution container (C), air hose connected to the gallery ceiling (D), and handle shovel inside the gallery during mineral extraction (E)

Table I

Sieve sizes for sample classification

\begin{tabular}{|l|c|}
\hline Sieve & Size $[\mathrm{mm}]$ \\
\hline$-8+10$ & 2.36 \\
$-4+8$ & 4.75 \\
$-1 / 4+4$ & 6.4 \\
$-3 / 8+1 / 4$ & 9.5 \\
\hline
\end{tabular}




\section{In situ mining through leaching}

Table II

Elemental composition of the samples

\begin{tabular}{|l|c|c|c|c|c|c|c|c|c|c|c|c|c|c|c|c|c|}
\hline Element & $\mathbf{S i}$ & $\mathbf{A l}$ & $\mathbf{C a}$ & $\mathbf{F e}$ & $\mathbf{M g}$ & $\mathbf{S}$ & $\mathbf{K}$ & $\mathbf{T i}$ & $\mathbf{C u}$ & $\mathbf{S r}$ & $\mathbf{C r}$ & $\mathbf{V}$ & $\mathbf{M o}$ & $\mathbf{M n}$ & $\mathbf{Z n}$ & $\mathbf{Z r}$ & $\mathbf{R b}$ \\
\hline Composition (\%) & 51.7 & 21.3 & 6.92 & 6.43 & 1.98 & 5.59 & 4.26 & 0.96 & 0.63 & 0.08 & 0.05 & 0.04 & 0.03 & 0.04 & 0.03 & 0.02 & 0.01 \\
\hline
\end{tabular}

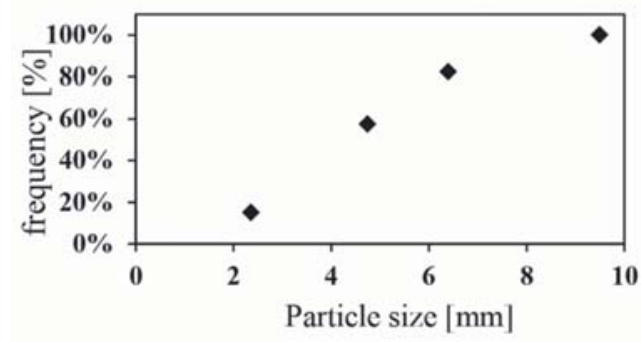

Figure 5-Cumulative frequency of sample granulometry

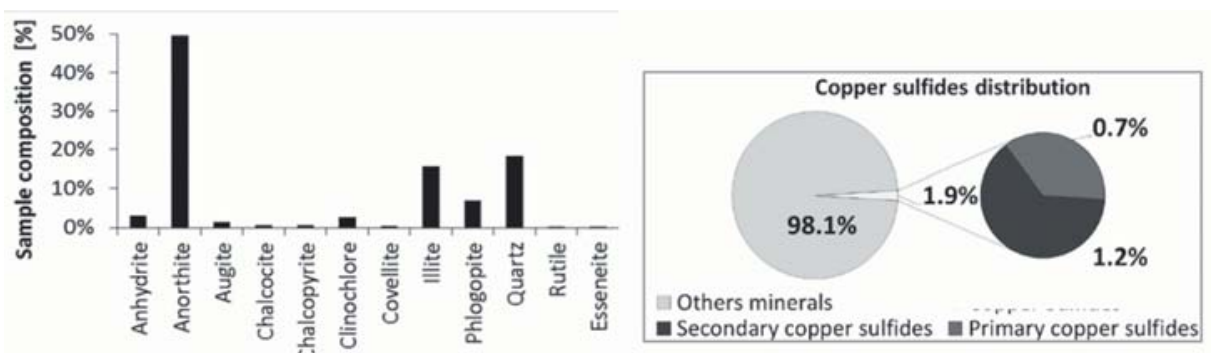

Figure 6-(A) Mineralogical composition of the samples and (B) copper sulphide content distribution

Table III

\section{Experimental cases and conditions}

\begin{tabular}{|l|c|c|c|c|c|c|c|}
\hline Case & Sample $\mathbf{( k g )}$ & $\mathbf{H}_{\mathbf{2}} \mathbf{S O}_{\mathbf{4}} \mathbf{( g / L )}$ & $\mathbf{F e}^{3+} \mathbf{( g / L )}$ & Initial density $\left(\mathbf{t} / \mathbf{m}^{\mathbf{3}}\right)$ & $\mathbf{T}\left({ }^{\circ} \mathbf{C}\right)$ & Artificial aeration & Material extraction \\
\hline Base case & 75 & 20 & 3 & 1.15 & 20 & No \\
Case 1a & 75 & 20 & 3 & 1.27 & No & No \\
Case 1b & 75 & 20 & 3 & 1.27 & 20 & No \\
Case 2 & 75 & 20 & 3 & 1.15 & 29 & No \\
Case 3 & 75 & 20 & 3 & 1.15 & 20 & No \\
\hline
\end{tabular}

Five experimental cases were developed (Table III). The base case considered the leaching of the sample without previous compression, at room temperature $\left(20^{\circ} \mathrm{C}\right.$ average $)$ and without artificially induced air flow. The effects of four variables were studied: density, extraction, temperature of the leaching solution, and air incorporation. To study the effect of compression, the density of the sample was increased by $10.4 \%$ from 1.15 to $1.27 \mathrm{t} / \mathrm{m}^{3}$. In the case of material extraction, a removal rate of $1.5 \mathrm{~kg} / \mathrm{d}$ for 7 days was considered. To study the influence of temperature, the temperature was increased incrementally up to an average of $29^{\circ} \mathrm{C}$, and to evaluate the effect ventilation, the air pump was used to provide $270 \mathrm{~L} / \mathrm{h}$ of air to the model. The laboratory protocol is shown in Figure 7.

\section{Results and discussion}

\section{Effect of compression}

The natural compression of the material by the overburden weight results in an increase in density and decreasing porosity with increasing depth (Fatt, 1952; Bass, 1980). The increase in pressure due to taller leach columns also leads to a reduction in the porosity and, therefore, a decrease in leaching efficiency (Dixon, 2007). During the laboratory experiments, increasing the material density by $10.4 \%$ led to a reduction of the recovery: $16.5 \%$ in case $1 \mathrm{a}$ and $13.4 \%$ in case $1 \mathrm{~b}$, in comparison to the $19.9 \%$ in the base case within the same period of time (Figure 8A). This represents a reduction of $17.1 \%$ and $32.6 \%$ in copper recovery for cases 


\section{In situ mining through leaching}

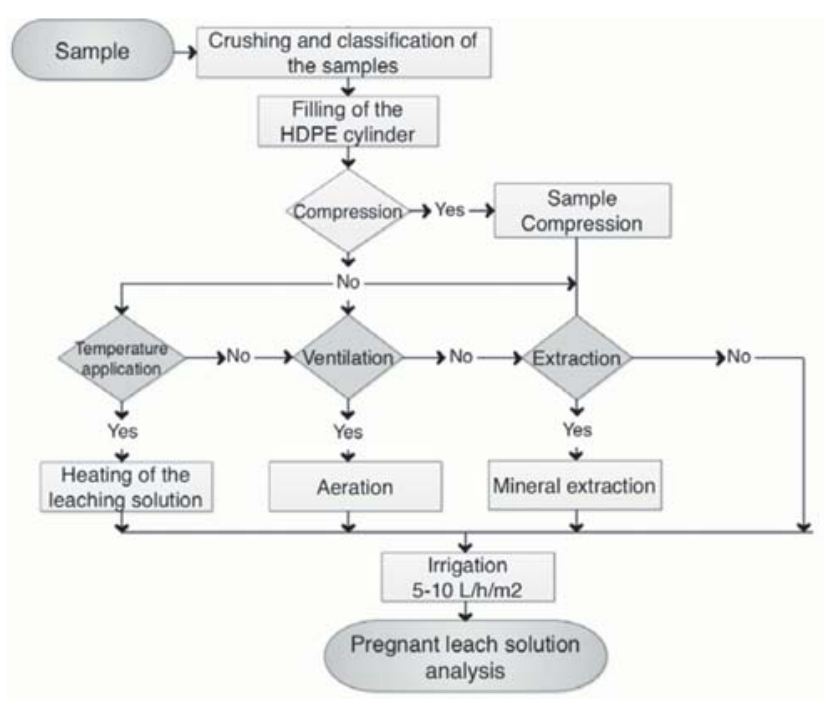

Figure 7-Experimental work flow

$1 \mathrm{a}$ and $1 \mathrm{~b}$, respectively. Therefore, the compression of the ore being leached must be considered in the future work to prevent over-estimation of the recovery through the leaching operation. The applied vertical stress must be defined according to the height of the stope.

\section{Effect of material extraction}

The effect of material extraction was studied in two cases, with and without initial compression of the sample and after 750 hours of irrigation. As indicated in Figure 8B, only the base case shows an increase in copper recovery after material extraction. Even though the results from the laboratory testing were inconclusive with regard to the effect of material extraction on copper recovery, the benefits of extraction cannot be dismissed as the removal of material had been shown to improve the permeability by creating zones of higher porosity (Kvapil, 1992) and could contribute to reordering of the fragments and channeling of the solution. Therefore, it is recommended to continue the study by extending the range of extraction and initial permeability.

\section{Effect of temperature}

During the leaching process, the temperature can rise naturally due to the exothermic nature of the sulphide oxidation reactions. The effect of the geothermal gradient $\left(1^{\circ} \mathrm{C}\right.$ for each $\left.100 \mathrm{~m}\right)$ should also be considered. The temperature may also be maintained artificially through heating of the leaching solution. High dependence of the metallurgical recovery on the temperature was observed by Lorca (2004). The increase in the temperature reduces the passivation of the sulphide minerals and makes the passivation layer less stable (Lorca, 2004; Pradhan et al., 2008). The activity of leaching microorganisms also improves with increasing temperature (Kelly et al., 2008). In the present study, copper recovery increased from $19.9 \%$ to $29.8 \%$ when the temperature of the leaching solution was increased from $20^{\circ} \mathrm{C}$ to $29^{\circ} \mathrm{C}$, representing a $49.7 \%$ improvement over the base case scenario (Figure 8C).

\section{Effect of aeration}

An air flow of $270 \mathrm{~L} / \mathrm{h}$ into the drawbell base increased the recovery from $19.9 \%$ to $33.8 \%$, which represents a $69.8 \%$ improvement over the base case scenario (Figure 8D).

\section{Summary of effects of selected variables}

The copper recovery in cases 2 and 3, (Figure 8D) shows the necessity of considering the effects of variables when designing the ISM method. The decision should be made based on the economic evaluation of the project. It is envisioned that there will be a trade-off between increasing mining and processing costs and increasing copper recovery, which will influence the net present value (NPV) estimation.

In addition to $\mathrm{pH}$, Eh, and copper measurements, the PLS was examined under the microscope, and microorganisms were detected. Considering that no chemical oxidant were added after the experiments began, the presence of microorganisms in the PLS allowed the ferric iron to regenerate during the leaching process.

Table IV shows a resumé of the experimental variables and copper recoveries.

\section{Kinetic analysis and modelling}

The leaching kinetics were described by the shrinking core
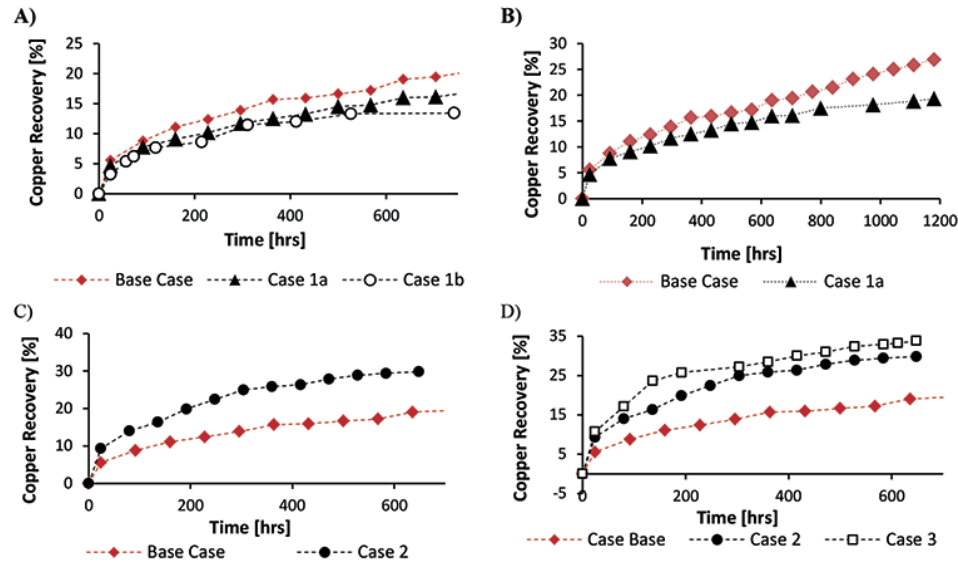

Figure 8-Influence of (A) compression, (B) material extraction, (C) temperature, and (D) aeration on copper recovery 


\section{In situ mining through leaching}

Table IV

Copper recovery for each experimental case

\begin{tabular}{|c|c|c|c|c|}
\hline Case & $\begin{array}{l}\text { Test duration } \\
\text { (hours) }\end{array}$ & Fixed variables & Changed variable & $\begin{array}{l}\text { Final copper } \\
\text { recovery }(\%)\end{array}$ \\
\hline Base case & 1180 & Temperature, aeration, density & - & 23.1 \\
\hline Case $1 \mathrm{a}$ & 1180 & Temperature, aeration & Density increased from 1.15 to $1.27 \mathrm{t} / \mathrm{m}^{3}$ & 16.5 \\
\hline Case $1 b$ & 743 & Temperature, aeration & Density increasedfrom 1.15 to $1.27 \mathrm{t} / \mathrm{m}^{3}$ & 13.4 \\
\hline Case 2 & 648 & Aeration, density & Temperature increased from $20^{\circ} \mathrm{C}$ to $29^{\circ} \mathrm{C}$ average & 29.8 \\
\hline Case 3 & 648 & Temperature, density & Aeration: from natural aeration to an artificial flow of $215 \mathrm{~L} / \mathrm{min}$ & 33.8 \\
\hline
\end{tabular}

Table $\mathrm{V}$

Chemical- or difussional-controlled reaction parameters according the shrinking core model

\begin{tabular}{|c|c|c|c|c|c|c|}
\hline & $\mathrm{R}^{2}$ chemical controlled & $\mathbf{R}^{2}$ diffusion controlled & Control type & $K_{\text {dif }}$ & $\tau$ (years) & $\Delta \% \tau^{*}$ \\
\hline Base case & 0.88 & 0.98 & Diffusion & $2 \times 10^{-5}$ & 6.6 & - \\
\hline Case 1a & 0.81 & 0.94 & Diffusion & $1 \times 10^{-5}$ & 10.7 & $\uparrow 62.1$ \\
\hline Case 1b & 0.80 & 0.92 & Diffusion & $9 \times 10^{-6}$ & 11.1 & $\uparrow 68.2$ \\
\hline Case 2 & 0.85 & 0.96 & Diffusion & $5 \times 10^{-5}$ & 2.2 & $\downarrow 66.7$ \\
\hline Case 3 & 0.80 & 0.94 & Diffusion & $7 \times 10^{-5}$ & 1.6 & $\downarrow 75.8$ \\
\hline
\end{tabular}

* Variation between the registered value in the base case and the respective case study

model. The reaction-controlled process is expressed by Equations [1] and [2] (Levenspiel, 1962). Equation [1] presents the relationship between the copper recovery $(X)$, the time of reaction $(t)$, and the theoretical time for the leaching reaction to proceed to completion $(\tau)$.

$$
\begin{aligned}
& t=\tau \cdot\left(1-(1-X)^{1 / 3}\right) \\
& \tau=(\rho \cdot R) / b \cdot k_{s} \cdot C_{A L}
\end{aligned}
$$

where $\tau$ is a function of the density of the solid ( $\rho$ the particle radius $(R)$, the molar mass $(b)$, the kinetic coefficient $\left(k_{S}\right)$, and the concentration of the leaching solution $\left(C_{A L}\right)$. On the other hand, the diffusional-controlled process is described by Equations [3] and [4]; in this case $(\tau)$ is also a function of the effective diffusion $\left(D_{e f f}\right)$.

$$
\begin{aligned}
& t=\tau \cdot\left[1-3 \cdot\left(1-X_{B}\right)^{2 / 3}+2\left(1-X_{B}\right)\right] \\
& \tau=\left(\rho_{B} \cdot R^{2}\right) / 6 b \cdot D_{\text {eff }} \cdot C_{A L}
\end{aligned}
$$

Table $\mathrm{V}$ shows the diffusional reaction controlling mechanism, which best describes the experimental results. Also shown are the experimentally determined $K_{\text {diff }}$ values and the theoretical time $(\tau)$ for completion.

Based on the diffusional-controlled equations, the copper recovery with time can be improved by decreasing the fragment size, increasing the temperature (increasing the effective diffusion through the product layer), increasing the concentration gradient, or decreasing the thickness of the diffusion layer, among other possibilities.

Using the shrinking core model, the maximum copper recovery is estimated at $t=10$ years (Figure 9). The estimation is developed for six different granulometries, considering the experimental results of the base case and case 3 . The effect of fragment size is greater in the case base than for case 3 . Case 3 (aertion study) resulted in the best experimental recovery during the leaching tests.

As shown in Figure 9, the difference in the estimated copper recovery $(X)$ between the base case and case 3 (including air flow) increases with particle size. This relationship is shown in Table VI.

\section{Business model and economic evaluation}

The second part of the investigation was focused on the feasibility and applicability of the ISM method. A business model was developed to investigate the feasible point of applying ISM. The case study was conducted on an orebody that could be considered as a mid-size mining operation in Chile. The orebody was exploited by conventional SLS, which was economically compared with the same orebody exploited by ISM.

\section{Mining and processing costs and investment}

Both initial cases considered a production rate of $1000 \mathrm{kt} / \mathrm{a}$. The capital and operational costs for the SLS were derived from a preliminary economic assessment developed for an ore deposit located in the north of Chile.

As indicated in Table VII, the mining cost will reach US\$16.28 per ton for conventional mining and US\$9.16 per ton for ISM. In the case of ISM, an additional $15 \%$ is incorporated for the leasing of the mining equipment.

According to Table VII, the main difference between the mining costs for these methods is due to the reduction in loading and hauling of ore, since in ISM only the portion corresponding to swelling is sent to the surface after blasting.

In terms of the operational processing plant costs, the conventional mining case includes primary and secondary crushing, agglomeration, stacking, leaching, solvent extraction (SX), and electrowinning (EW). Considering these 


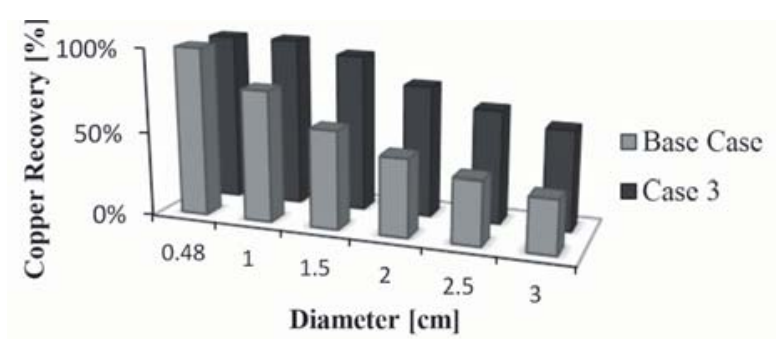

Figure 9-Estimations of copper recovery applying the shrinking core model for six different particle sizes. Estimations made for two cases: base case and case 3 , at $t=10$ years

\begin{tabular}{|c|c|}
\hline \multicolumn{2}{|c|}{$\begin{array}{l}\text { Estimated copper recovery }(\%) \text { for the base case } \\
\text { and case } 3 \text { for six different fragment sizes at } t=10 \\
\text { years }\end{array}$} \\
\hline Particle diameter $(\mathrm{cm})$ & XCase 3-XBase Case (\%) \\
\hline $\begin{array}{l}0.48 \\
1.0 \\
1.5 \\
2.0 \\
2.5 \\
3.0\end{array}$ & $\begin{array}{c}0 \\
22 \\
35 \\
32 \\
29 \\
27\end{array}$ \\
\hline
\end{tabular}

Table VII

Operating costs in conventional mining and ISM

\begin{tabular}{|l|c|c|}
\hline & $\begin{array}{c}\text { Conventional } \\
\text { US\$ per ton }\end{array}$ & $\begin{array}{c}\text { ISM } \\
\text { US\$ per ton }\end{array}$ \\
\hline Production drilling & 0.53 & 0.79 \\
Production blasting & 0.38 & 0.56 \\
Haulage & 0.62 & 0.12 \\
Transport & 0.93 & 0.18 \\
Production fortification & 0.85 & 0.55 \\
Production drill-holes & 1.09 & 1.42 \\
Mining services & 2.12 & 0.86 \\
Sub-total (considering ISM leasing) & 6.52 & 4.50 \\
Maintenance cost & 7.26 & 1.42 \\
Stope preparation & 2.50 & 3.25 \\
Total & 16.28 & 9.16 \\
\hline
\end{tabular}

operations, the processing cost in conventional mining method would be US\$15.3 per ton. It is expected that ISM would not require such operations as crushing, agglomeration, and stacking. By benchmarking of different operations in Chile, it was established that approximately $40.9 \%$ of the processing costs correspond to SX-EW operations and $59.1 \%$ to the other operations (comminution processes, agglomeration, stacking, and leaching). Thus, the plant cost for ISM reaches approximately US\$6.26 per ton. Based on the Florence project in Arizona (SRK, 2010), the additional operational cost of solution injection and recovery in ISM is considered at US\$0.28 per pound $\mathrm{Cu}$.

The mine investment includes the development of ramps, ventilation equipment, shafts, and mining equipment. The mine investment has been estimated as US\$6.334 million for conventional mining. For ISM, it is estimated that less investment would be required, due to the less intensive use of equipment as only a fraction of the material is hauled to the surface, which will required an investment of US\$526000.

The capital expenses of the processing plant for conventional mining include the costs of equipment for comminution and agglomeration, leaching, SX, EW, tank farm, and civil works among other operations. Therefore, the processing plant investment for conventional mining has been estimated at US\$38.54 million. ISM does not entail comminution and agglomeration, but includes the development of injection and recovery wells. The total plant investment for ISM corresponds to US\$19.11 million. This includes a scaled average cost of US\$3.27 million for the wellfield, based on the case studies of San Manuel, Florence, and Gunnison mines (Williamson, 1998; SRK, 2010; M3, 2011).

The capital and operating costs of mining and processing plant are summarized in Table VIII. The copper recovery in the conventional mining method, for this economic evaluation, is considered constant and equal to $85 \%$, while copper recovery in ISM is dependent on the leaching kinetics (Figure 10A). The volume of PLS considered to be sent to the processing plant per year in ISM is presented in Figure 10B.

\section{Table VIII \\ Main economic parameters used to compare ISM and conventional mining}

\begin{tabular}{|l|c|c|c|}
\hline Parameter & Unit & Conventional & ISM \\
\hline Maximum copper recovery & $\%$ & 85 & 60 \\
Copper price & US\$/lb & 2.80 & 2.80 \\
Discount rate & $\%$ & 10 & 10 \\
Mine operational expenses & US\$/ton & 16.3 & 9.2 \\
Processing plant operational expenses & US\$/ton & 15.28 & 6.82 \\
Wellfield operational expenses & US\$/lb Cu & 0 & 0.28 \\
Mine capital expenses & US\$ million & 6.334 & 0.526 \\
Processing plant capital expenses & US\$ million & 38.5 & 15.8 \\
Wellfield capital expenses & US\$ million & 0 & 3.3 \\
Production rate & kt/a & 1,000 & 1,000 \\
\hline
\end{tabular}

B)

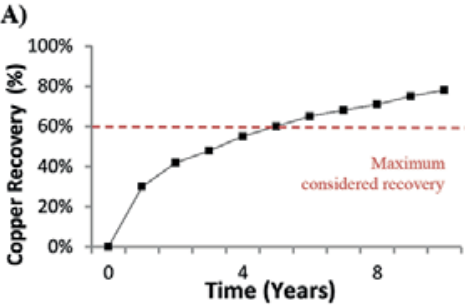

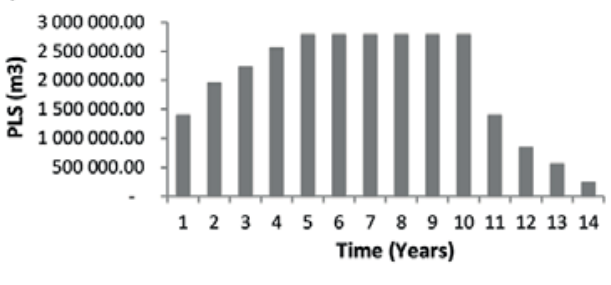




\section{In situ mining through leaching}
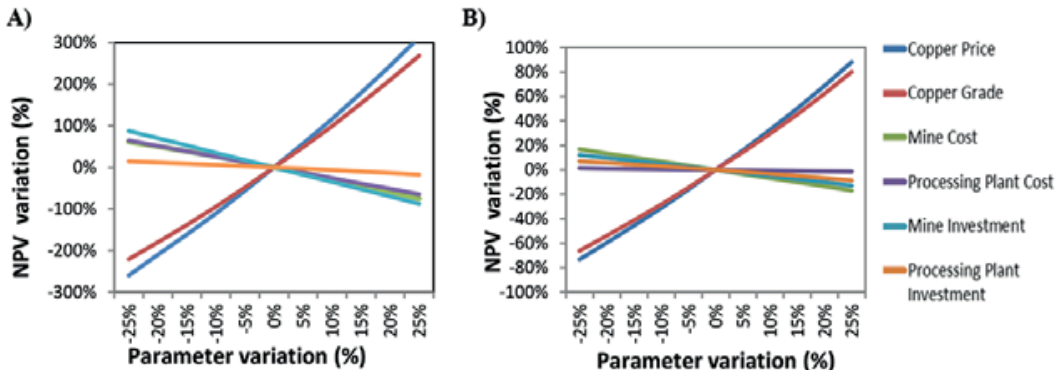

Figure 11-Sensitivity analysis of NPV for (A) conventional mining and (B) for ISM

Table IX

Economic indices estimated for conventional and ISM perations

\begin{tabular}{|l|c|c|c|c|c|c|c|c|}
\hline & $\mathbf{k t / a}$ & $\begin{array}{c}\text { kt Cu / } \\
\text { year }\end{array}$ & $\begin{array}{c}\text { Recovery } \\
\text { (\%) }\end{array}$ & $\begin{array}{c}\text { Initial capex } \\
\text { (US\$ million) }\end{array}$ & $\begin{array}{c}\text { NPV } \\
\text { (US\$ million) }\end{array}$ & $\begin{array}{c}\text { NPVI } \\
\text { IRR } \\
\text { (\%) }\end{array}$ & $\begin{array}{c}\text { Average cash cost } \\
\text { (US\$/lb) }\end{array}$ & $\begin{array}{c}\text { Life of mine } \\
\text { (years) }\end{array}$ \\
\hline Conventional & 1000 & 10.9 & 0.85 & 64.4 & 60.95 & 0.95 & 27 & 1.39 \\
ISM case A & 1000 & Variable & Max. 60\% & 23.1 & 62.05 & 2.68 & 37 & 1.19 \\
ISM case B & Variable & 10.9 & Max. 60\% & 27.5 & 87.45 & 3.19 & 62 & 1.07 \\
ISM case C & 1000 & Variable & Maax. 67\% & 24.8 & 94.28 & 4.07 & 60 & 1.12 \\
\hline
\end{tabular}

\section{NPV}

According to the economic evaluation, the net present value (NPV) of both the conventional mining and ISM operations is on average, equal to US\$61 million (US\$60.95 million and US\$62.05 million respectively). According to the NPV, internal rate of return (IRR), and NPV/investment (NPVI), both methods are profitable. The average cash cost per pound copper is US\$1.39 for SLS and US\$1.19 for ISM. ISM also presents a better IRR ( $27 \%$ versus $37 \%)$ and NPVI $(0.95$ versus 2.68) than conventional mining. Different procedures should be evaluated to enhance the ISM method by increasing the copper recovery, which will improve the NPV, making it more profitable and cost-effective compared to conventional mining.

\section{Sensitivity analyses}

Drilling and blasting can increase the leaching efficiency due to the increase in the leachable surface. A sensitivity analysis was carried out to evaluate the impact of this operation on the operating expenses (OPEX). The analysis showed that OPEX is more sensitive to drilling and blasting than to hauling and loading and mine services.

A sensitivity analysis for copper price, grade, costs, and investment was also completed. As shown in Figure 11, the NPV of both methods is more sensitive to the price of copper and grade than to the OPEX and capital expenditure (CAPEX) of the project. A price decrease of $25 \%$, which corresponds to a drop of US\$2.17 per pound, results in a negative NPV for the conventional mining case. In the same scenario, ISM maintains a positive NPV of US\$18.1 million. When the copper grade is decreased by $25 \%$, the NPVs are US $\$ 2.2$ million for SLS and US\$26.4 million for ISM. Accordingly, under unfavourable price and grades conditions, the ISM method represents a better alternative.

After evaluation of conventional mining and ISM at equal tonnages of blasted material per year (ISM case A), two additional cases were considered:
- Case B-equal tonnages of copper per year were assumed for ISM and SLS. Based on the leaching kinetics, to recover the same tonnage of copper for ISM, a higher tonnage of ore should be blasted in a shorter period of time

- Case C - the estimated copper recovery, based on the shrinking core model, in ISM is assumed to be increase up to a maximum of $67 \%$ by leaching at elevated temperature. The recovery in SLS is maintained at $85 \%$. To achieve the increase in copper recovery in ISM, additional technology will be required to heat the leaching solution.

Table IX shows the summary of the economic indices estimated for the conventional and ISM cases.

As shown in Table IX, the NPV of the SLS case study is less than that for ISM. The registered NPVs for ISM are A $<\mathrm{B}$ $<\mathrm{C}$; Case B considers an accelerated mine plan (a greater tonnage of ore must be blasted and irrigated per year than in case A), and the life of mine is shorter. This results in the cash flow being less affected by the discount rate. A greater NPV is achieved in case $\mathrm{C}$ due to the increase in the leaching kinetics by heating of the leaching solution.

The capital expenses of ISM are less than those estimated for conventional mining. ISM considers leasing of mining equipment as is less hauling- and loading-intensive than $\mathrm{SLS}$. The increases of CAPEX in cases B and C are due to the larger number of stopes required in a shorter period of time (case B) and additional technology required in the processing plant (case C).

Based on the results, to optimize the NPV of the project, it is essential to improve control of the parameters that affect copper recovery. This can be achieved, for example, by increasing the surface area of the mineral in contact with the leaching solution by blasting to increase fragmentation, increasing the temperature or the aeration, and increasing the activity of leaching microorganisms. There will be a trade-off between increased recovery of copper over time and increased operational cost. 


\section{In situ mining through leaching}

As shown schematically in Figure 12A, the increase in the OPEX of ISM (heating of solutions or more extensive drilling and blasting) increases the recovery of copper over time. This effect was observed in case $\mathrm{C}$. The rise in OPEX will have a negative impact on the NPV (Figure 12B). Considering the effects of operational expenditures and that the copper recovery does not increase steadily over time, the ratio of OPEX to copper recovery will decrease as maximum recovery is approached.

Based on Figure 12, Figure 13 shows the NPV-OPEX relationship for ISM. Unlike conventional mining, the increase in OPEX will results in a higher NPV for ISM (green zone) as a consequence of higher copper recovery over time. However, the OPEX/recovery ratio will increase when a slower leaching kinetic is reached or maximum recovery of copper is achieved. When the increase in the OPEX adversely affects the net value, the project's NPV will be negatively affected (red zone). The maximum recovery rate depends on several factors, such as mineralogy and the operational parameters considered in the project.

\section{Conclusion}

A laboratory model and an experimental protocol to evaluate in situ mining (ISM) were developed. These allowed a preliminary estimate to be made of the recovery of copper from sulphide deposits. The model design allowed compression and extraction of the mineral sample contained in the leaching column as well as the application of aeration to the ore sample and heating of the leaching solution. The experimental parameters used for air flow and the irrigation rate were taken from the literature, while the size distribution was arbitrarily defined. To evaluate the efficiency of leaching for a given deposit, the post-blasting size fragmentation should be considered in the experimental evaluation.

The results of the experimental test work showed that increasing the material density reduced the copper recovery on average by $24.8 \%$. Thus, ignoring the effect of compression may lead to overestimation of the copper recovery in an ISM operation. With respect to the mineral extraction operation, only the base case showed an increase in the copper recovery. Further studies should be conducted to assess the benefits of, for example, improving the permeability, on recovery. Increasing the temperature of the leaching solution as well aeration of the model through the gallery improved the copper recovery in comparison to the base case by $49.7 \%$ and $69.8 \%$ respectively. Stope ventilation and heating of the leaching solution should therefore be economically evaluated. In relation to the shrinking core model, a similar kinetic behaviour was observed in the

A)

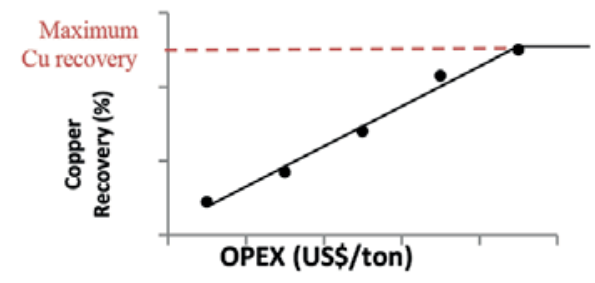

leaching of the copper sulphide samples, where the kinetic data best fitted the diffusion-controlled reaction in all the study cases.

According to the economic evaluation, ISM effectively had lower mining and processing costs and required lower investment than the conventional mining case. In the case studied, with a maximum metallurgical recovery of $60 \%$, ISM and SLS present a NPV of approximately US\$61-62 million. By accelerating stope development and irrigation of the ore, the NPV reaches US\$87.4 million, representing an increase of $40.9 \%$ for ISM. On the other hand, the acceleration of leaching kinetics at elevated temperature results in a NPV of US\$94.3 million, an increase of $51.9 \%$. According to the economic index and the sensitivity analysis, the NPV of ISM is more sensitive to metallurgical recovery than to costs. This makes it possible to maximize the project NPV by increasing the copper recovery, even when this results in increased operational and capital costs. However, the relation between costs, recovery, and NPV is neither constant over time nor equivalent among different mineral deposits, since it will depend on the leaching kinetics. The relationship between these variables will not be persistent since the achievable recovery is subject to an upper limit. The maximum OPEX and CAPEX that lead to a profitable increase in metallurgical recovery should be calculated for each case to establish the cost limits under which it is possible to optimize the benefit of the ISM method.

\section{Acknowledgments}

The authors wish to acknowledge financial support from the Advanced Mining Technology Center (AMTC), Chile. We are grateful to Dr Asieh Hekmat for her helpful collaboration.

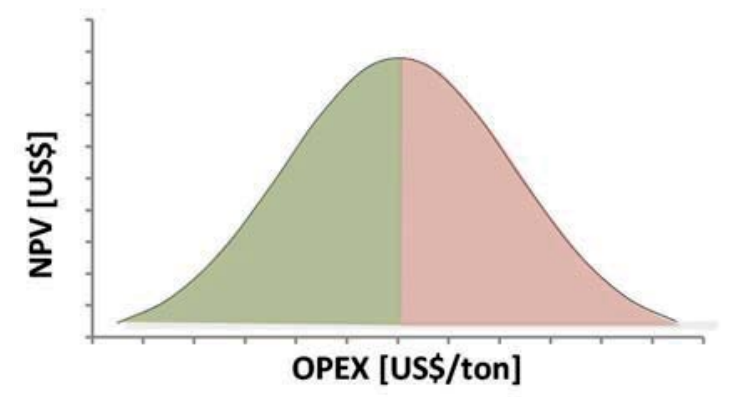

Figure 13-Schematic curve of the OPEX versus NPV for the in situ mining method

B)

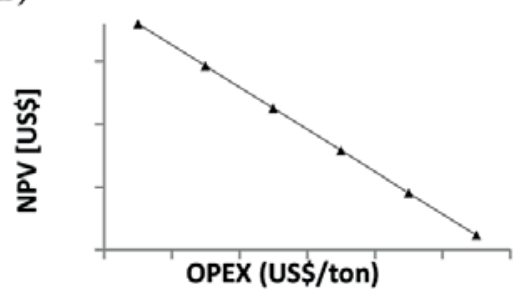




\section{In situ mining through leaching}

\section{Abbreviations}

CAPEX Capital expenditure

ISL In situ leaching

ISM In situ mining

IRR Internal rate of return

NPV Net present value

OPEX Operating expenditure

PLS Pregnant leach solution

SLS Sublevel stoping

\section{References}

Akin, H., Gotz, H., Loewer, R., CATChPole, G., and Becker, J. 1996. Mining uranium by the in situ leach method. ATW Int. Atomwirtschaft Atomtechnik, vol. 41, no. 2. pp. 94-97.

BASs, D. 1987. Properties of reservoir rocks. Petroleum Engineering Handbook. Society of Petroleum Engineers, Richardson, TX. pp. 1-33.

Bearman, R. 2007. Total system design for comminution. Proceedings of the Ninth Mill Operators Conference, Fremantle, Australia. Australasian Institute of Mining and Metallurgy, Melbourne. pp. 3-8.

BRADY, B. 1995. Some prospective mining applications of fluid injection in rock. Annual Conference of the Australasian Institute of Mining and Metallurgy, Newcastle. Inglaterra.

Boreck, D., Djahanguiri, F., and Miller, N. 1991. Rock mass characterization for designing underground leaching stopes. SME-AIME Annual Meeting, Colorado, USA.

ERIKSON, J. 1978. Underground in situ mining-a new mining method. Mining Engineering, vol. 30, no. 11. pp. 1532-1534.

EXCElsior Mining CoRp. 2011. Gunnison Copper Project: NI 43-101 Technical Report. Tucson, AZ.

FATT, I. and DAvIS, D. 1952. Reduction in permeability with overburden pressure. Journal of Petroleum Technology, vol. 4, no. 12. p. 329.

Harmsen, J., Roes, A., and Patel, M. 2013. The impact of copper scarcity on the efficiency of 2050 global renewable energy scenarios. Energy, vol. 50. pp. 62-73.

Herrera, D. 1987. Estudio de lixiviación in situ en mina El Teniente. Thesis, Facultad de Ciencias Físicas y Matemáticas, University of Santiago, Chile.

International Atomic Energy Agency (IAEA). 2001. Manual of acid in situ leach uranium mining technology. IAE-TECDOC-1239. Vienna, Austria

HaRtman, H. 1992. Solution mining: in situ techniques. SME Mining Engineering Handbook, 2nd edn. Vol. 2. SME, Littleton, CO.

KVAPIL, R. 1992. Sublevel caving. SME Mining Engineering Handbook, vol. 2. Hartman, H.L. (ed.). SME, Littleton, CO. pp 1789-1814.

KeLLY, R.M. 2008. Biooxidation capacity of extremely thermophilic archaea under bioenergetic challenge. Biotechnolnology and Bioengineering, vol. 58. pp. 617-624.

LeVENSPIEL, O. 1962. Ingeniería de las Reacciones Químicas. Wiley, New York. pp. 393-409.

Liu, J. and Brady, H. 1998. Evaluation of velocity-dependent in situ leaching processes: Single-porosity model. Metallurgical and Materials Transactions, vol. 29B. pp. 1227-1234.

LLoRente, E. 1991. Minería Química. ITGE: Instituto Tecnológico GeoMinero de España.
LoRCA, C. 2004. Bioleaching study for low grade primary sulfides at Collahuasi. Hydro-Sulfides 2004. Proceedings of the International Colloquium on Hydrometallurgical Processing of Copper Sulfides, Universidad de Chile, Santiago, 16-19 April 2004.

M3 Engineering \& Technology Corporation. 2011. NI 43-101 Technical Report Preliminary Economic Assessment - Cochise County, Arizona, USA.

Morais, C., Gomiero, L., and ScassiotTi, W. 2008. Leaching of uranium ore from Caetités facilities. Bahia state, Brazil. Hydrometallurgy 2008: Proceeding of the Sixth International Symposium. Young, C., Taylor, P., and Anderson, C. (eds.). Society for Mining, Metallurgy, and Exploration, Littleton, $\mathrm{CO}$.

MudD, G.M. 2001. Critical review of acid in situ leach uranium mining: 1. USA and Australia. Environmental Geology, vol. 41, no. 3-4. pp. 390-403.

NRC. 1997. Final environmental impact statement to construct and operate the Crownpoint uranium solution mining project, Crownpoint, New Mexico. Washington DC

O Gorman, G., Michaelis, H., and Olson, G. 2004. Novel in situ metal and mineral extraction technology. Final Report. Department of Energy, Liitle Bear Laboratories, Golden, CO. http://digital.library.unt.edu/ark:/ 67531/metadc787962/

Ortiz, O., CAnchari, G., and Soto, C. 2010. Minería in situ. Su aplicación en un yacimiento de cobre oxidado. Revista del Instituto de Investigacionea FIGMMG, vol. 13, no. 25. pp. 31-41. http://sisbib.unmsm.edu.pe/ bibvirtual/publicaciones/geologia/v13_n25/pdf/a05v13n25.pdf

Pradhan, N., Nathsarma, K., Srinivasa, K., SukLa, L., and Mishra, B. 2008. Heap bioleaching of chalcopyrite: a review. Minerals Engineering, vol. 21. pp. 355-365.

SchlitT, W. 1992. Solution mining: surface techniques. SME Mining Engineering Handbook, 2nd edn. Hartman, H.L. (ed.). Vol. 2. Chapter 15.2. SME, Littleton, CO.

SRK Consulting. 2010. NI 43-101 Preliminary Economic Assessment for the Florence Project. Arizona, USA.

Sullivan, J. and OstreA, E. 1981. Factor governing the entry of solution into ores during leaching. US Bureau of Mines.

Tshilombo, A., Petersen, J., and Dixon, D. 2002. The influence of applied potentials and temperature on the electrochemical response of chalcopyrite during bacterial leaching. Minerals Engineering, vol. 15. pp. 809-813.

USOTA (US. Office of Technology Assessment). 1988. Copper: technology and competitiveness. https://www.princeton.edu/ ota/disk2/1988/ 8808_n.html

Venter, R. and Boylett, M. 2009. The evaluation of various oxidants used in acid leaching of uranium. Hydrometallurgy Conference 2009. Southern African Institute of Mining and Metallurgy, Johannesburg. pp. 445-455.

Williamson, C. 1998. Hydrologic mechanisms and optimization of in situ copper leaching: case study-BHP Copper, San Manuel, Arizona. Doctoral thesis, Department of Hydrology and Water Resources, University of Arizona.

WNA (World Nuclear Association). 2014. In situ leach (ISL) mining of uranium. http://www.world-nuclear.org/info/Nuclear-Fuel-Cycle/ Mining-of-Uranium/In Situ-Leach-Mining-of-Uranium/ [Accessed 4 August 2014]. 